\title{
Epidemiology of Bovine Trypanosomosis in Ethiopia
}

\section{Tulu D*}

Ethiopian Institute of Agricultural Research, Tepi Agricultural Research Center, Ethiopia

*Corresponding author: Dereje Tulu, Ethiopian Institute of Agricultural Research, Tepi Agricultural Research Center, P.O. Box 34, Tepi, Ethiopia, Email: derejetulu5@gmail.com

\section{Review Article \\ Volume 3 Issue 1}

Received Date: January 22, 2019

Published Date: February 02, 2019

DOI: $10.23880 /$ eij-16000118

\section{Abstract}

Trypanosomosis is a protozoan disease, mostly transmitted by the tsetse fly, Glossina spp., which causes severe disease livestock in Ethiopia. The disease results in loss of livestock and agricultural productivity with serious socioeconomic consequences. Bovine trypanosomosis is widely distributed in western and southwestern part of the country. Six species of trypanosomes are recorded in Ethiopia and the most important trypanosomes in terms of economic loss are the tsetse transmitted species: T. congolense, T. vivax and T. b. brucei. Annual estimated losses for Ethiopia as a result of trypanosomosis is roughly $\$ 200$ million, in terms of mortality and morbidity losses in livestock excluding the failure to utilize fertile land for crop and livestock production and the costs included in controlling the disease. The pathogenesis of trypanosomosis depends on the pathogenicity of the strains; the host breed, age, sex and skin type. The diagnosis of trypanosomosis includes clinical diagnosis and direct parasitological examination. Bovine trypanosomosis could be treated by trypanocidal drug for therapeutic and prophylactic purpose. Bovine trypanosomosis can be controlled by early treatment of infected animal and vector control. Thus, it is recommended that an appropriate use of trypanocidal drugs, integrated prevention and control program should be implemented to reduce the impact of the disease.

Keywords: Cattle; Ethiopia; Epidemiology; Tsetse fly; Trypanosomosis

\section{Introduction}

Ethiopia possesses the largest livestock population in Africa. It is primarily kept on small holdings where it provides draft power for crop production, manure for soil fertility and fuels, serves as a sources of family diet and cash income [1]. Despite possessing large livestock population, Ethiopia fails to optimally utilize this resource due to different constrains affecting the livestock subsector. Shortage of nutrition, reproductive insufficiency, management problems and animal disease are the major constraints. One of the diseases hampering the livestock subsector is trypanosomosis [2].
Trypanosomosis is a complex disease of protozoa that is caused by different species of unicellular parasites (Trypanosome) found in the blood and other tissues of vertebrates including livestock, wildlife and people [3]. Bovine trypanosomosis is one of the diseases that caused by the flagellated protozoal parasite belong to the genus trypanosoma.

Trypanosomosis limited the expansion of livestock herds particularly in Africa were the presence of the tsetse fly denies access to woodland and savanna areas with good grazing potential [4]. It is a serious constraint to agricultural production (livestock and mixed crop- 


\section{Epidemiology international journal}

livestock farming) in extensive areas of tsetse infestation in about $10 \mathrm{~km}^{2}$ of the tropical Africa [5]. Currently about 3 million livestock die every year from tsetse fly transmitted trypanosomosis. In this region at least 46 million cattle are exposed to the risk of contracting tsetse-borne trypanosomosis and millions of sheep, goats, donkeys, camels and horses are also at risk [6].

Tsetse transmitted trypanosomosis in Ethiopia widely distributed in western and southwestern lowlands and the major river valleys. It is a major problem to the utilization of large land resources [3]. The loss of land fertility caused by drought, overpopulation and overstocking of much land in the marginal, high temperature, low rainfall areas of northern regions led to the resettlement of the affected rural population and their livestock in more potentially productive areas, many of which are tsetse infested. Furthermore the expansion of tsetse population into higher altitude areas brings them into contact with previously unaffected livestock [4].

Since it was a serious constraint to agricultural production in extensive areas of the tsetse fly infested low land areas, an extensive tsetse and trypanosomosis surveys were carried out in Didesa and Abay river system [7]. Tsetse transmitted animal trypanosomosis still remain as one of the largest causes of livestock production losses in Ethiopia [8]. The effects of trypanosomosis is not only the direct losses resulting from mortality, morbidity, infertility of the infected animals and costs of controlling the disease, but also includes indirect losses, which involves livestock and animal power based crop production from the huge fertile tsetse infected areas [9]. Annual estimated losses for Ethiopia as a result of trypanosomosis is roughly US $\$ 200$ million, in terms of mortality and morbidity losses in livestock (excluding utilization of fertile land for crop and livestock production) and the costs included in controlling the disease [10].

Six species of trypanosomes are recorded in Ethiopia and the most important trypanosomes in terms of economic loss in domestic livestock are the tsetse transmitted species: T. congolense, T. vivax and T.b. brucei [4]. Tsetse flies in Ethiopia are confined to western and south-western parts of the country between $33^{\circ}$ and $38^{\circ} \mathrm{E}$ longitude and $5^{\circ}$ and $12^{\circ} \mathrm{N}$ latitude. It is estimated to cover an area of 140, 000-220, $000 \mathrm{~km}^{2}$ [11]. Tsetse infested areas follow the major river systems Abay (Blue Nile), Baro, Akobo, Didessa, Ghibe and Omo. Five species of Glossina (Glossina morsitans submorsitans, G. pallidipes, G. tachinoides, G.f. fuscipes and $G$. longipennis) have been recorded in Ethiopia [4]. Tsetse transmitted animal trypanosomosis still remain as one of the largest causes of livestock production losses in Ethiopia [8]. Therefore the objectives of this paper are to review epidemiological and economic significant of bovine trypanosomosis in Ethiopia.

\section{Bovine Trypanosomosis}

\section{Definition of the disease}

Bovine Trypanosomosis (Nagana) is a disease complex caused by several species of unicellular protozoan parasites of the phylum Sarcomastigophora, order Kinetoplastida, family Trypanosomatidae and genus Trypanosoma. It is mainly transmitted cyclically by the genus Glossina (Tsetse flies), but also transmitted mechanically by several biting flies like Tabanids, Stomoxys, Haematopota and Chrysops. The disease can affect various species of mammals but, from an economic point of view, tsetse-transmitted trypanosomosis, is particularly important in cattle [10].

\section{Etiology}

Trypanosomes are flagellated protozoan parasites that live in the blood and other body fluids of vertebrate hosts. They swim in body fluids by flagellum, boring their way between cells. They generally possess a kinetoplast and undergo cyclical development in an arthropod vector. Their biological adaptations, morphology and pathogenicity are fascinating and are being extensively studied [12]. In Ethiopia there are three important species of trypanosomes are recorded in cattle. These are T. congolense, T. vivax and T. brucei. $T$. vivax and T. congolense are the main pathogens of cattle. Trypanosomosis outside "tsetse belt" is caused by mechanically biting flies; the main etiological agent of mechanically transmitted trypanosomosis is T.vivax [10]. T. congolense resides in the subgenus Nannomonas, a group of small trypanosomes with medium-sized marginal kinetoplast, lack of free flagella and poorly developed undulating membranes. T. vivax is a member of the subgenus Duttonella, a group of trypanosomes with large terminal kinetoplast, distinct free flagella and inconspicuous undulating membrane, although this organism is considered to be less pathogenic for cattle than $T$. congolense. This trypanosome readily persists in areas free of tsetse, where it is transmitted mechanically by biting flies or contaminated needles, syringes and surgical instruments. T.b. brucei resides in the subgenus Trypanozoon. T.b.brucei is an extremely polymorphic trypanosome occurring as short, stumpy organisms without flagella, long slender organisms with distinct flagella and intermediate forms that are usually flagellated [4].

\section{Life cycle}

The life cycle of trypanosome in tsetse involves cyclical development for varying length of time, depending on species and ambient temperatures. Most tsetse-transmission begins when blood from a 


\section{Epidemiology international journal}

trypanosome infected animal is ingested by the tsetse fly. The trypanosome loses its surface coat, multiplies in the fly, then reacquires a surface coat and becomes infective. Trypanosoma brucei species migrate from the gut to the proventriculus to the pharynx and eventually to the salivary glands; the cycle for T. congolense stops at the hypo pharynx and the salivary glands are not invaded; the entire cycle for T.vivax occurs in the proboscis. The animal-infective form in the tsetse salivary gland is referred to as the metacyclic form. The life cycle in the tsetse may be as short as one week with T. vivax or extend to a few weeks for T. brucei species (Figure 1) $[13,14]$.

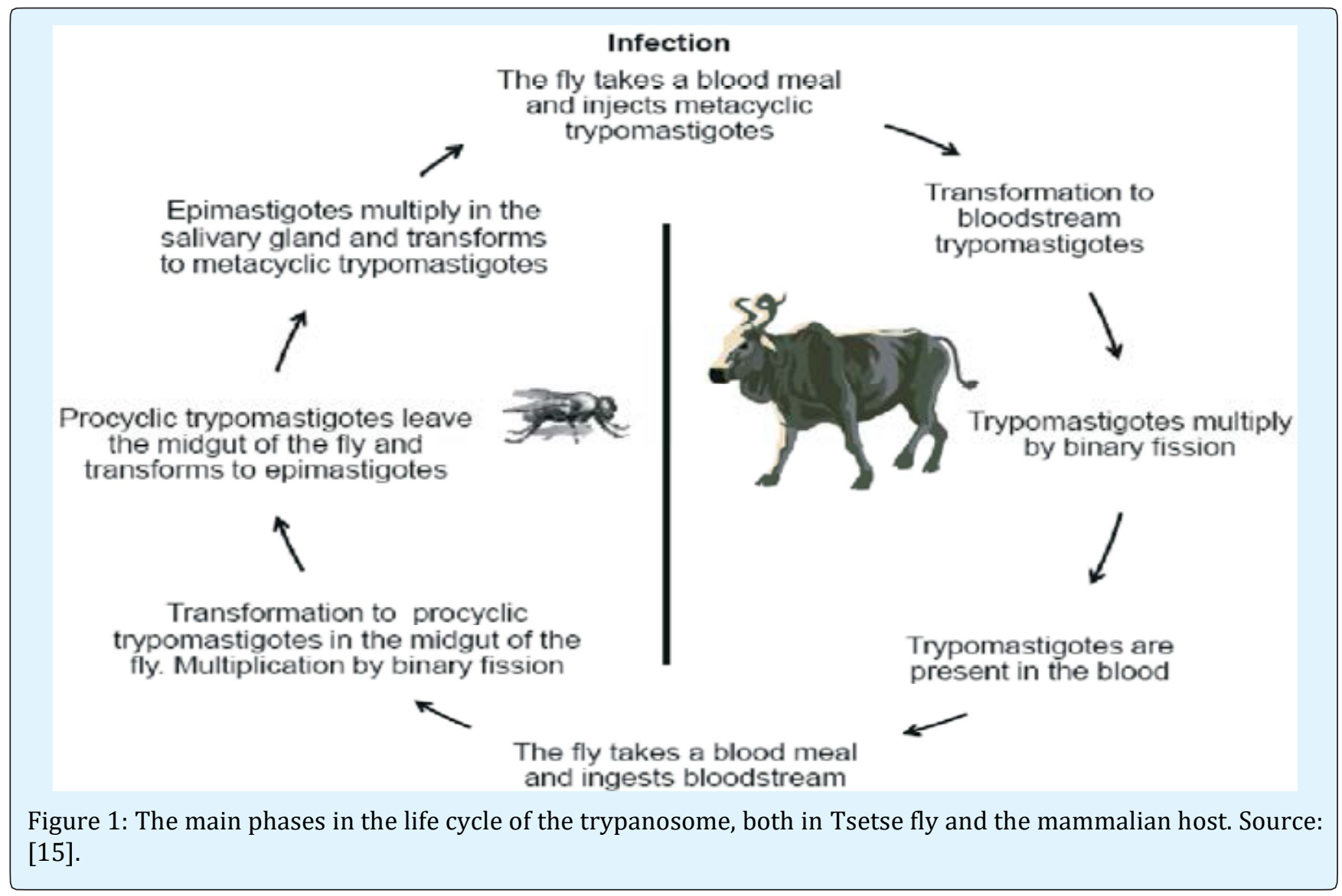

\section{Pathogenesis}

Pathogenesis of trypanosomosis in most species is a progressive, but not always fatal disease and the main features are anemia, tissue damage and immunosuppression. Metacyclic trypanosomes are inoculated intradermally as the fly feeds. They multiply at this site provoking a local skin reaction (Chancre), which is most pronounced in a fully susceptible host and may be slight or absent with some strains or species of trypanosomes. Within the chancre, metacyclic parasites change to trypomastigote form, enter the bloodstream directly or through the lymphatics and initiate characteristic intermittent parasitemias. Their behavior thereafter depends largely on the species of trypanosome transmitted and the host [16]. T. vivax usually multiplies rapidly in the blood of cattle and is evenly dispersed throughout the cardiovascular system, whereas T. congolense tends to be aggregated in small blood vessels and capillaries of the heart, brain and skeletal muscle. Both species exert their effect mainly by causing severe anemia and mild to moderate organ damage. The anemia has a complex pathogenesis involving mainly increased erythrophagocytosis, some hemolysis and dyshemopoiesis [17]. Very acute infection with T. vivax in cattle causes parasitemias and disseminated intravascular coagulation (DIC) with hemorrhages. T. brucei and rarely T. vivax have the capability of escaping from capillaries into interstitial tissues and serous cavities where they continue to multiply. The cerebrospinal fluid is often invaded by $T$. brucei alone or mixed with other species or as a relapse after an apparently successful treatment. Animals chronically infected with any pathogenic trypanosome may develop concurrent and even fatal bacterial, viral and other protozoan infections as a result of immunosuppressant $[18,19]$.

\section{Epidemiology of Trypanosomosis}

The epidemiology of trypanosomosis is highly dependent on the parasite, vector and host factors. 
Trypanosome species occur in a variety of genotypes with different strains, virulence, immunogenicity and response to chemotherapeutic agent. Since the parasite infects a wide range of animals including wild animals which constitute the reservoirs of the disease, the epidemiology of trypanosomosis is extremely complex [20]. The degree of risk to which domestic animals are exposed to the trypanosomosis depends on the species and density of tsetse present, infection rate in tsetse, species and strain of trypanosomes, source of infection (wild or domestic animals) and feeding preference of the flies [21].

Trypanosomosis is a disease, which is cyclically and acyclically transmitted by different species of tsetse flies and other flies [22]. In principle, any species may occasionally be transmitted contaminated syringe and surgical instrument [3]. Transmission by tsetse fly is a complex mechanism in which the fly remains lifelong carrier. In the vector trypanosome changes through several morphological distinct stages (amastigotes, promastigote and epimastigote) until it reaches trypomastigote (metacyclic stage) which is infective for mammals [20]. The tsetse fly becomes infected with trypanosomes when feeding on an infected animal. Once the trypanosomes are ingested they lose the surface coat, develop a mitochondrion and undergo a number of developmental stages before they become infective for the mammalian host. Although the developmental stages are similar for the three species of trypanosomes, the sites within the tsetse which they occur are different [23].

\section{Distribution of bovine trypanosomosis in Ethiopia}

Trypanosomosis is an important disease of livestock in Ethiopia. Six pathogenic species of trypanosomes exist in Ethiopia, namely T.vivax, T. congolense, T.b. brucei, T. evansi, T. equiperdum and T. rhodesiense. But the most important trypanosomes in the country are $T$. vivax and T.congelense. Both species affect a great number of cattle which are the most important species of the domestic animals in Ethiopia. Due to its extensive distribution, $T$. vivax is more important than $\mathrm{T}$. congolense. Most of the above listed species of trypanosomes are limited in distribution to Africa which is the home of the cyclical vector. But the mechanically and venerally transmitted trypanosomes have a cosmopolitan distribution [24]. T. vivax is found in the entire country except in the highlands, which are 2500 meters above sea level. The wide spread of $T$. vivax is due to its adaptation to mechanical transmission by biting flies in areas outside tsetse fly belt. The distributions of T. congolense and T.b. brucei have been limited nearly to the area of the cyclical vector, the Ethiopian tsetse fly belt. This is due to the fact that both species of trypanosomes are not adapted to acyclical transmission. Therefore, the diseases which are caused by T. congolense and T.b. brucei are limited to southern and western areas of the country (Table 1) [24].

\begin{tabular}{|c|c|c|c|}
\hline Trypanosome & Vector & Mainly affected host & Regional distribution \\
\hline T. congolense & Tsetse & Cattle & Amhara \\
\hline T. vivax \& T. brucei & Tsetse & Cattle & Benshangul-Gumuz, Gambella \\
\hline T. vivax & Biting flies & Cattle & All over Ethiopia \\
\hline
\end{tabular}

Table 1: Trypanosome species reported in Ethiopia.

Estimates made decades ago indicates that a total area of 220, $000 \mathrm{~km}^{2}$ is infested with different species of tsetse flies in which case livestock reared in this area are exposed to various levels of trypanosomes risk
(Figure 2). More than twelve million livestock populations which are reared in this area are at risk of contracting tsetse-transmitted trypanosomosis in Ethiopia [25].

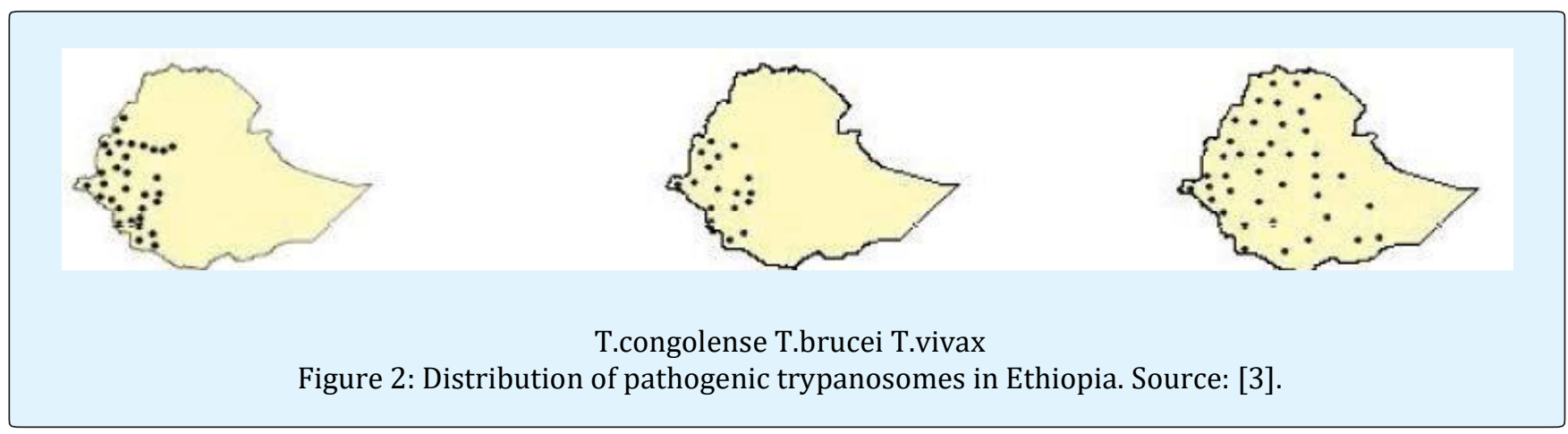




\section{Risk Factors}

Host related factors: The effect of infection varies with the host in that most wild animal and some domestic establish a balance with the parasite and remain as clinically normal carriers for long periods. Specifically, some breeds of cattle indigenous to Africa can tolerate light to moderate challenge with tsetse flies by limiting the multiplication of trypanosomes in their blood and by apparently warding off the infection, especially $\mathrm{T}$. vivax [26]. It is both genetic and environmental in origin and the level of tolerance varies. Crossbreeds of indigenous Taurine and Zebu animals are also more tolerant than pure breed zebu. However, due to the uncertain genetic makeup of animals within these socalled breeds and crossbreeds, the level of trypanotolerance may also vary with individual animals within a given category and it can be overcome by heavy tsetse challenge, malnutrition, or other stress factors [17]. The Sheko breed classified as a humpless short horn is the only known breed of Taurine type in eastern Africa which exhibit trypanotolerance [27]. The breed is found in the Bench-Maji zone of southern Region in the south-western parts of Ethiopia [15].

Environmental related factors: The density of tsetse population in the area and the level of their contact with the host, will determine the level of infection. This is further influenced by the vectorial capacity of the fly and the availability of its preferred host, which may not be livestock. Trekking of cattle through tsetse-infested vegetation is a risk nomadic farmer's face from time to time and the risk is even greater where cattle routes converge, for example, at major bridges or watering holes [11]. Agricultural and industrial developments generally lead to a lowering of tsetse density by destroying its habitat, whereas the establishment of game or forest reserves provides large numbers of preferred hosts or a suitable habitat for tsetse, respectively. Herds located near such reserves are therefore at a higher risk [13]. The vector for trypanosomosis, the tsetse fly, requires a habitat that strongly influenced by ecological and climatic features particularly rainfall, soil type, temperature and vegetation type. Fly larvae can die as a result of drying soils. Extreme temperature, particularly above $36^{\circ} \mathrm{C}$ and below $10^{\circ} \mathrm{C}$ also led to adult fly mortality through starvation and water loss via respiration [28]. Cumulative effects of long rainy season or dry season are important in influencing advances and recession in tsetse population [29]. The effect of altitude on tsetse distribution is through its effect on climate, mainly temperature. Different species of tsetse flies require particular vegetation type that would provide an optimal condition for growth and survival. Vegetation is also important that provides shelter for their hosts. All environmental factors that affect the tsetse fly indirectly affect the occurrence of trypanosomosis [29].
Pathogen related factors: In cattle, T. vivax generally produces a higher level of parasitemia than other species. And since, its life cycle in the tsetse is also shorter; T. vivax is more readily transmitted than the others when animals are newly introduced into a tsetse infested area. Higher parasitemias also facilitate mechanical transmission. On the other hand, T. brucei is rarely detectable by direct examination of cattle blood, even though infection can be confirmed through other diagnostic methods [30].

\section{Impact of Bovine Trypanosomosis}

\section{Economic Impact}

According to the Food and Agricultural Organization of the United Nations, trypanosomosis is probably the only disease which has profoundly affected the settlement and economic development of a major part of SSA of the approximately 7-10 million $\mathrm{km}^{2}$ of land that are infested by tsetse fly, only20 million cattle are raised. Under different circumstances this land could support more than 140 million cattle and increase meat production by 1.5 million tons [31]. Trypanosomosis threatens 50 million head of cattle in SSA. Every year, trypanosomosis causes about 3 million deaths in cattle while approximately 35 million doses of trypanocidal drugs are administered to enable livestock to survive in tsetse-infested areas. While the economic losses in cattle production alone are in the range of US\$1.0-1.2 billion, the indirect impact engendered by the disease on the total agriculture-livestock production is estimated at US $\$ 4.5$ billion a year. The overall negative impact extends to the access and availability of cultivable areas, changes in land use and exploitation of natural resources, restriction of opportunities for diversification and intensification of agricultural activity. The magnitude of the problem requires a multidisciplinary approach for effectively promoting sustainable agriculture and rural development strategies [32]. The disease directly affect the milk and meat productivity of animals, reduces birth rates, increases the abortion rates as well as mortality rate; all of these affect the herd size and herd composition [33]. Indirect impact of trypanosomosis mostly lies on crop production through the availability and cost of animals that provide traction power [34]. Animal trypanosomosis reduces work efficiency of oxen cultivation, reducing access to animal traction or discourages the introduction of draught animals in to crop farming [35]. Evaluation on effect of trypanosomosis incidence on the productivity of oxen used for traction showed that relative inefficiency in the high risk area was $38 \%$ less efficient than oxen in the low risk area [36].

Additional traction capacity allows farmers expand the area that they cultivate, increase yield of existing crops; grow different mix of crops or allocated labor 


\section{Epidemiology international journal}

land and fertilizer more efficiently. In other study discussed the economic benefits from intervening against bovine trypanosomosis. These authors reported significant benefits especially for Ethiopia, because of its very high livestock densities and the importance of animal traction. The estimated maximum benefit per square kilometer of tsetse infested area is US\$10,000. Consequently, the total maximum benefits from dealing with bovine trypanosomosis in Ethiopia could be as much as US\$ 1 billion [37].

\section{Zoonotic Impact}

The animal pathogens do not infect humans, but animals can serve as reservoirs of T. brucei rhodesiense and T. brucei gambiense, the causes of human sleeping sickness, which are morphologically indistinguishable from T. brucei brucei. Human infections result from tsetse bites, generally in game parks, forest reserves and along streams or other rural setting [38].

\section{Major Clinical Findings in Bovine Hosts}

There are no pathgnomonic signs that would help in pinpointing a diagnosis. The general clinical sign are there but variations determined by the level of tsetse challenge, the species and strain of the trypanosome, the breed and management of the host. Acute episodes last for a few days to a few weeks from which the animal dies or lapses in to a sub-acute to chronic stage, or the illness may be chronic from the beginning. Chronic cases may run a steady course, may be interrupted by periodic incidents of severe illness, or undergo spontaneous recovery [19]. The basic clinical syndrome appears after an incubation period of 8-20 days. There is fever, which is likely to be intermittent and to last for a long period. Affected animals are dull, anorexia and apathetic, have a watery ocular discharge and lose condition. Superficial lymph nodes become visibly swollen, mucous membranes are pale, diarrhea occasionally occurs and some animals have edema of the throat and underline. Estrus cycles become irregular, pregnant animals may abort and semen quality progressively deteriorates. The animal becomes very emaciated, cachectic and dies within 2-4 months or longer. Thin, rough-coated, anemic, lethargic cattle with generalized lymph node enlargement are said to have 'fly-struck 'appearance. Furthermore, intercurrent bacterial, viral, or other parasitic infections may mask or complicate the basic clinical syndrome [39].

\section{Diagnosis}

Diagnosis of Trypanosomosis in tsetse, humans or domestic livestock is a basic requirement for epidemiological studies as well as for planning and implementing chemotherapy and for monitoring vector control operations. Accurate diagnosis of trypanosome infection in livestock is required for a proper appreciation of the disease in any geographical locality. Besides clinical diagnosis, parasitological, serological and molecular methods with varying degrees of sensitivity and specificity are available for the diagnosis of trypanosomosis [40].

\section{Clinical Diagnosis}

Severity of disease varies with species and age of the animal infected and the species of trypanosome involved. T. congolense and $T$. vivax are highly pathogenic for cattle and $T$. brucei infections are generally regarded as being low pathogenicity. The primary clinical signs are intermittent fever, anaemia and weight loss. Cattle usually have a chronic course with high mortality, especially if there is poor nutrition or other stress factors [41]. Clinical diagnosis is found to have a good sensitivity (78\%) but a low specificity (27\%) when compared to parasitological tests [42]. Under field conditions, in the absence of simple and portable diagnostic tools or access to laboratory facilities, veterinarians could rely on clinical sings and direct parasitological diagnosis to screen and treat cases of bovine trypanosomosis presented by farmers [42].

\section{Parasitological Diagnosis}

These are made by placing a drop of blood on a microscope slide and covering with a cover-slip. The blood is examined microscopically using an $\mathrm{x} 40$ objective lens. Approximately 50-100 fields are examined. Trypanosomes can be recognized by their movement among the RBC. The method is simple, inexpensive and gives immediate results. Depending on the trypanosome size and movements, a presumptive diagnosis can be made of the trypanosome species [43]. Final confirmation of the species is made by the examination of the stained preparation. The diagnostic sensitivity of the method is generally low, but depends on the examiner's experience and the level of parasitaemia. Sensitivity can be improved significantly by lysing the RBCs before examination using a haemolytic agent such as sodium dodecyl sulfate [44]. Thick Blood Smear Technique is simple and relatively inexpensive, but results are delayed because of the staining process. Trypanosomes are easily recognized by their general morphology, but may be damaged during the staining process. This may make it difficult to identify the species [45]. Usually, both a thin and thick smear is made from the same sample. Thick smears contain more blood than thin smears and, hence, have a higher diagnostic sensitivity. Thin smears on the other hand allow trypanosome species identification. Trypanosome species can be identified by the following morphological characteristics (Table 2) [46]. 


\begin{tabular}{|c|c|c|c|c|c|c|}
\hline Species & $\begin{array}{c}\text { Site of } \\
\text { development } \\
\text { in tsetse fly }\end{array}$ & Free flagellum & kinetoplast & $\begin{array}{l}\text { Undulating } \\
\text { membrane }\end{array}$ & $\begin{array}{c}\text { Size in } \\
\text { micrometer }\end{array}$ & $\begin{array}{l}\text { Size and motility in wet } \\
\text { film }\end{array}$ \\
\hline T.vivax & Proboscis & present & Large, terminal & $\begin{array}{l}\text { Non } \\
\text { prominent }\end{array}$ & $20-26$ & $\begin{array}{l}\text { Large, extremely active } \\
\text { travels the whole field very } \\
\text { quickly, pausing occasionally }\end{array}$ \\
\hline T.brucei & $\begin{array}{l}\text { Mid-gut, } \\
\text { salivary gland }\end{array}$ & $\begin{array}{l}\text { Present in all } \\
\text { but not in } \\
\text { stumpy form }\end{array}$ & $\begin{array}{l}\text { Small, sub } \\
\text { terminal } \\
\text {, central }\end{array}$ & prominent & $15-35$ & $\begin{array}{l}\text { Large, rapid movement in } \\
\text { confined areas }\end{array}$ \\
\hline T.congolense & $\begin{array}{l}\text { Mid-gut, } \\
\text { proboscis }\end{array}$ & Absent & $\begin{array}{l}\text { Medium, sub } \\
\text { terminal, } \\
\text { marginal }\end{array}$ & $\begin{array}{c}\text { Not } \\
\text { prominent }\end{array}$ & $9-18$ & $\begin{array}{c}\text { Small, sluggish active, } \\
\text { adheres to red blood cells by } \\
\text { anterior end }\end{array}$ \\
\hline
\end{tabular}

Table 2: Morphological characteristics of Trypanosome species.

\section{Treatment, Control and Prevention}

Trypanosomosis can be treated with trypanocidal drug for therapeutic and prophylactic purpose. A therapeutic drug includes diminazene aceturate, homidium bromide and homidium chloride. Prophylactic drugs for cattle include homidium (bromide, chloride) and isomethamidium [47].

The control of trypanosomosis in enzootic countries involves control of tsetse fly population, prophylactic treatment and good husbandry of animals at risk and use of trypanotolerant animals. Control of tsetse has been successfully attempted, but reinvasion is frequent if the land is not properly utilized. More recent methods involved the use of insecticides applied strategically in the form of ground and aerial spraying over large expanses of land [48]. As tsetse is sensitive to insecticides and no resistance has developed, considerable successes were achieved in some countries. However, spraying insecticides is costly and harmful to the environment. These harmful effects are considerably reduced if the insecticides. Other effective methods involve targets impregnated with insecticides and traps that attract and catch tsetse. These are simple and cheap and can be constructed and maintained by local communities. Furthermore, they do not pollute the environment and are suitable for both small and largescale fanning [49]. Another method is the sterile insect technique. Since the female tsetse only mates once in a life time, this technique is theoretically able to eradicate a targeted tsetse species in areas where other methods have been used to reduce its density but it is expensive.
Finally, it should be stated that development of the land for agriculture, industries, highways, etc. will effectively destroy the habitat for tsetse flies [19]. Attempts at trypanosomosis control have also been directed to prophylactic dosing with chemicals such as homidium (bromide, chloride) and isomethamidium. Prophylaxis is used along with other methods in areas where there is a heavy tsetse challenge. The prophylactic effect is supplemented by the development of antibodies and the total period of protection may be as long as 5 months. However, it is customary to give four or five treatments per year [50]. The productivity response to this pattern of treatment is good if general husbandry is also adequate. The downside of this approach is that it has reportedly led to drug resistance in many countries. In the absence of a vaccine, control methods must combine reduced exposure to the vectors (large scale tsetse trapping and pour-on applications) with strategic treatment of exposed animals (chemotherapy Chemoprophylaxis) along with use of trypanotolerant animals when feasible [19].

Trypanocidal drug resistance is increasingly reported all over Africa and now present in 21 subSaharan countries including Ethiopia [51]. Drug resistance is the heritable loss of sensitivity of a microorganism to a drug to which it was before sensitive. The exposure of trypanosomes to sub therapeutic concentrations of trypanocidal drugs, the treatment frequency and the degree of drug exposure of the parasite population are important factors influencing the development of drug resistance (Figure 3) [52,53]. 


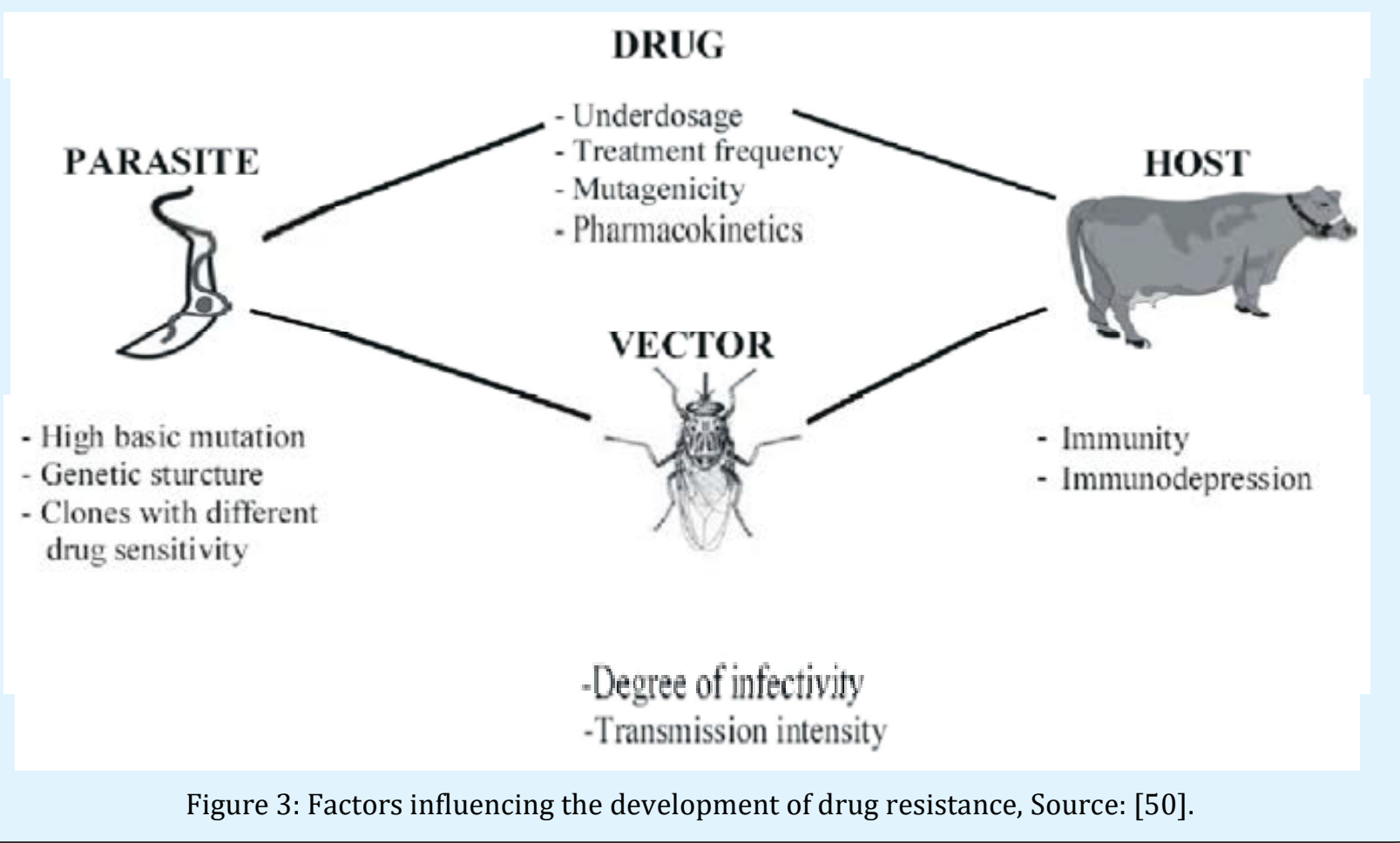

\section{Conclusion and Recommendations}

Conclusively bovine trypanosomosis is a serious protozoa disease that has a great economic impact throughout Ethiopia. Bovine trypanosomosis is the main constraint to cattle production and rural agricultural activity in the country. Tsetse transmitted trypanosomosis is widely distributed in western and southwestern part of the country mainly in the major river basins and imposes great losses on the economic development of the country. On the other hand drug resistance is continuing to be the main problem as a result of extensive and uncontrolled use of trypanocidal drugs. Based on the above remarks, the following recommendations are suggested.

- In view of the so far known epidemiological situation of bovine trypanosomosis in Ethiopia further studies may be needed to understand current status of the disease.

- Sustainable community based integrated control methods need to be designed and applied in affected areas.

- Judicious use of chemotherapy deserves serious attention.

- Training and updating of animal health professionals on the current epidemiology and control practices of animal trypanosomosis should be given due attention.

\section{References}

1. ILRI (2002) Food security in sub-Saharan Africa, Nairobi, Kenya. A paper reporting, pp: 148.

2. Bekele J, Asmare K, Abebe G, Ayelet G, Esayas G (2010) Evaluation of Deltamethrin applications in the control of tsetse and trypanosomosis in the southern rift valley areas of Ethiopia. Vet Parasitol 168(3-4): 177-184.

3. Uilenberg G (1998) A field guide for diagnosis, Treatment and Prevention of African animal trypanosomosis; W.P. FAD, Rome, pp: 43-35.

4. Getachew A (2005) Review Article Trypanosomosis in Ethiopia. Acad J Ani Dis 1(1): 11-15.

5. Rogers D, Robinson T (2004) Tsetse distribution. In: Maudlin (Eds.), The trypanosomosis, pp: 139179.

6. Reid RS, Kruska RL, Wilson CJ, Perry BD (1998) The Impact of Controlling Tsetse Fly on Land-Use and the Environment. In: Lyman J, et al. (Eds.), Spatial and Temporal Dynamics of African Farming Systems.

7. Slingenbergh J (1992) Tsetse control and agricultural development in Ethiopia. World Anim Rev 70(71): 30-36. 
8. Tulu D, Gebeyehu S, Aseffa N, Negera C (2018) Prevalence of bovine trypanosomosis and associated risk factor in Jimma Horro District, Kellem Wollega Zone, Western Ethiopia. J Vet Med Ani Health 10(8): 185-191.

9. NTTICC (2004) National tsetse and Trypanomososis Investigation and Control Center report for the period $7^{\text {th }}$ July 2001- $6^{\text {th }}$ July 2002 Badelle, Ethiopia, pp: 3.

10. Desquesnes M, Davila A (2002) Applications of PCRbased tools for detection and easy method for species-specific diagnosis of Trypanosoma species in cattle. Vet Parasitol 110: 171-180.

11. NTTICC (2002) National tsetse and Trypanosomosis Investigation and control center report for the period 7 June 2003 -6 July 2004, Bedelle, Ethiopia, pp: 1-4.

12. Magona J, Mayende J, Olaho-Mukani W, Coleman P, Jonsson N, et al. (2003) Comparative study on the clinical, parasitological and molecular diagnosis of bovine trypanosomosis in Uganda. Onderstepoort J Vet Res 70(3): 213-218.

13. OIE (1982) Report on the $8^{\text {th }}$ meeting of the international working group Trypanosoma evansi. Paris.

14. Dumesa T, Demessie Y (2015) Review on Tsetse Transmitted Bovine Trypanosomosis in Ethiopia. Euro J Appl Sci 7(6): 255-267.

15. Stein J (2011) Trypanotolerance and Phenotypic Characteristics of Four Ethiopian Cattle.

16. Jordon A (1996) Trypanosomiasis Control and tsetse research Laboratory, Bristol, pp: 13-19.

17. Loses G, Ikede B (1972) Review on pathology of diseases in domestic and laboratory animals caused by Trypanosoma congolense, T. vivax, T. brucei, $T$. rhodesiense and T. gambiense. Vet Path 9(1): 1-79.

18. Luckins A, Gray A (1978) An extravascular site of development of Trypanosoma congolense. Nature 272(5654): 613-614.

19. Radostits O, Blood D, Gay C (1994) Veterinary Medicine: A text book of cattle, sheep, goat, pigs and horses, $8^{\text {th }}$ (Edn.), BaillierTindall, UK. pp: 15311536.

20. Urquart GM, Armour J, Dunncan JL, Dunn AM, Jennings FW (1995) Veterinary Parasitology. The University of Glasgow, Elbs (Edn.), pp: 203-212.
21. MacLennan KJR (1980) Tsetse transmitted trypanosomosis in relation to the rural economy. Wild Anim Rev 36: 2-17.

22. Mulligan $H$ (2006) The African Trypanosomiasis, London, George Allen and Unwin Ltd., pp: 950.

23. Getachew A (1991) The Integrity of the Hypothalamic Pituitary Adrenal Axis in Boran (Bos indicus) Cattle Infected with Trypanosoma congolense. PhD Thesis, Brunel University of West London, UK.

24. Zeleke D (1982) Trypanosomiasis in Ethiopia, Proceedings of the $3^{\text {rd }}$ International Symposium on Veterinary Epidemiology and Economics.

25. Leta S, Habtamu Y, Alemayehu G, Ayele B, Chanie M, et al. (2015) Analysis of Habitat Suitability for the Major Tsetse species in Ethiopia using high resolution environmental data sets and Maxent modeling technique. National symposium on "Trends and challenges in Adoption of Science, technology and innovation in local development endeavors" Wollega University, pp: 32.

26. Murray M (1988) Trypanotolerance, its criteria and genetic and environmental influences. Proceedings of a meeting held in Nairobi, Kenya from the $23^{\text {rd }}$ 27the November 1987 organized by the International Livestock Center for Africa and the International Laboratory for Research on Animal Diseases, ILCA/ILRAD, pp: 133-151.

27. Rege JEO (1999) The state of African cattle genetic resources, Classification framework and identification of threatened and extinct breeds. Anim Genet Resour Inform 25: 1-25.

28. Moore N, Messina J (2010) A Landscape and Climate Data Logistic Model of Tsetse Distribution in Kenya. PLoS ONE 5(7): e11809.

29. Leak SGA (1999) Tsetse Biology and Ecology: Their Role in the Epidemiology and Control of Trypanosomosis. CABI publishing in association with the ILRI, pp: 152-210.

30. Rebeski D, Winger E, Van Rooij E, Schoch R, Schuller W, et al. (1999) Pitfalls in the application of enzyme-linked immunoassays for the detection of circulating trypanosomal antigens in serum samples. Parasitol Res 85(7): 550-556.

31. Reid RS (1997) Impacts of trypanosomosis on landuse and the environment in Africa: state of our knowledge and future directions. In proceeding of the $24^{\text {th }}$ meetings of international scientific council for trypanosomosis Research and control (ISCTRC), Maputo, Mozambique, OAU/ISTRC, pp: 500-514. 
32. Mattioli RC, Slingenbergh J (2013) Programme against African Trypanosomiasis

(PAAT) Information System.

33. Swallow BM (1999) Impacts of Trypanosomiasis on African agricultures international Livestock Research institute, Nairobi, Kenya, pp: 1-46.

34. Swallow BM (2000) Impact of Trypanosomiasis on African Agriculture. PAAT Technical and Scientific Series, FAO. Rome. Int J Anim Vet Adv 2 (2): 47-50.

35. Omotainse SO, Kalejaiye JO, Dede P, Dada AJ (2004) The current status of tsetse and animal trypanosomiasis in Nigeria. Vom J Vet Sci 1: 1-9.

36. Swallow BM, Mulatu W, Leak SGA (1995) Potential demand for a mixed public-private animal health input: evaluation of a pour on insecticide for controlling tsetse-transmitted trypanosomiasis in Ethiopia. Prev Vet Med 24(4): 266-275.

37. Shaw AP, Cecchi G, Wint GR, Mattioli RC, Robinson TP (2014) Mapping the economic benefits to livestock keepers from intervening against bovine trypanosomosis in Eastern Africa. Prev Vet Med 113(2): 197-210.

38. Blood D, Radostits O (2000) Diseases caused by protozoa, A textbook of the diseases of cattle, pigs, goats and horses. $7^{\text {th }}$ (Edn.), Oxford: ELBS, pp: 1012-1015

39. Connor R, Van den Bossche P, Coetzer J, Tustin R (2004) Infectious diseases of livestock, $2^{\text {nd }}$ (Edn.), Cape Town: Oxford University Press, 1: 251.

40. Dagnachew S (2004) Epidemiology of bovine trypanosomosis in the Abay basin areas of northwest Ethi opia, MSc thesis, Addis Ababa University, Faculty of Veterinary Medicine, Debre zeit, Ethiopia, pp: 151-157.

41. Riviere J, Popich M (2009) Veterinary Pharmacology and therapeutics. 9th (Edn.), Blackwell cross, pp: 1174-1175.

42. Soulsby E (1982) Helminths, arthropods and protozoa of domestic animals. $7^{\text {th }}$ (Edn.), UK, British Library Cataloguing, pp: 539-543.

43. Woo P (2000) The haematocrit centrifuge technique for the diagnosis of African trypanosomiasis. Acta Trop 27(4): 384-386.
44. Ndao M, Pandey VS, Zinsstag J, Pfister $\mathrm{K}$, Vanmeirvenne N (1995) Evaluation of Sodium Dodecyl-Sulfate (Sds) As a Hemolytic Agent for the Detection of Microfilariae and Trypanosomes in the Blood of Cattle. Ann Soc Belge Med Trop 75(2): 145148.

45. Taylor KA (1998) Immune responses of cattle to African trypanosomes: protective or pathogenic? Int J Parasitol 28(2): 219-240.

46. Geysen D, Delespaux V, Geerts S (2003) PCR-RFLP using Ssu-rDNA amplification as identification of animal trypanosomes; a review and perspectives. Vet Parasitol 109: 213-231.

47. Achenef M, Bekele B (2013) Drug and Drug Resistance in Africa Animal Trypanomosis. European J Appl Sci: 5 (3): 84-91.

48. Getachew A, Eley RM, ole-MoiYoi OK (1993) Reduced responsiveness of hypothalamic-pituitaryadrenal axis in Boran (Bos indicus) cattle infected with Trypanosoma congolense. Acta Endocrinol 129(1): 75-80

49. Boulange A, Katende J, Authie E (2002) Trypanosoma congolense expression of a heat shock protein 70 and initial evaluation as a diagnostic antigen for bovine trypanosomosis. Exp Parasitol 100(1): 6-11.

50. Eisler M, Lessard P, Masake R, Moloo S, Peregrine A (1998) Sensitivity and specificity of antigen-capture ELISAs for diagnosis of Trypanosoma congolense and Trypanosoma vivax infections in cattle. Vet Parasitol 79(3): 187-201.

51. Chitanga S, Marcotty $T$, Namangala B, Van den Bossche P, et al. (2011) High Prevalence of Drug Resistance in Animal Trypanosomes without a History of Drug Exposure. PLoS Negl Trop Diss 5(12): e1454.

52. Greets S, Holmes PH (1998) Drug management and parasite resistance in bovine Trypanosome in Africa, PAAT technical and scientific series No.1 FAO, Rome.

53. Elnasri H ( 2005) Prevalence and Ranking of Bovine trypanosomosis in Unity State, Sudan, MSc thesis, University of Khartoum, Faculty of Veterinary Medicine, Unity State, Sudan, pp:1-76. 